\title{
PROKARYOTIC AND VIRAL COMMUNITY STRUCTURE IN THE SINGULAR CHAOTROPIC SALT LAKE SALAR DE UYUNI
}

\author{
$M^{\mathrm{a}}$ Dolores Ramos-Barbero ${ }^{1}$, José M. Martínez ${ }^{2}$, Cristina Almansa ${ }^{1}$, Nuria Rodríguez ${ }^{3}$, \\ Judith Villamor ${ }^{1}$, María Gomariz ${ }^{1}$, Cristina Escudero², Sergio Rubin ${ }^{2,4}$, Josefa Antón ${ }^{1 *}$, \\ Manuel Martínez-García ${ }^{1}$, Ricardo Amils ${ }^{2,3}$
}

\section{*Correspondence to: anton@ua.es}

${ }^{1}$ Department of Physiology, Genetics and Microbiology, Universidad de Alicante, Alicante, Spain; ${ }^{2}$ Centro de Biología Molecular Severo Ochoa, Universidad Autónoma de Madrid (CBMSO, CSIC-UAM), Cantoblanco, 28049 Madrid, Spain ; ${ }^{3}$ Centro de Astrobiología (CAB, INTA-CSIC), 28055 Torrejón de Ardoz, Spain; ${ }^{4}$ Centro Nacional de Investigaciones Biotecnológicas, CNIB, Bolivia

This article has been accepted for publication and undergone full peer review but has not been through the copyediting, typesetting, pagination and proofreading process which may lead to differences between this version and the Version of Record. Please cite this article as doi: 10.1111/1462-2920.14549 


\section{Originality Significance Statement}

In this work, we characterize, for the first time, the viral community present in the singular system Salar de Uyuni, which harbours high concentrations of $\mathrm{Mg}$ and $\mathrm{Li}$, along with the changes experienced by the viral and host assemblages and their relationship with seasonal environmental parameters. Physico-chemical and microbial community composition was rather sampling-site-specific with an uncommon dominance of a single bacterial genus (frequently Salinibacter sp.) albeit different from previously cultured strains. Viral metagenomics showed that viral assemblages, although constituted by the same morphotypes found in salt lakes and salterns worldwide, were also sample specific but clearly distinct from those detected in other hypersaline systems, underlying the peculiarities of this unusual environment. 


\section{Summary}

Salar de Uyuni (SdU) is the largest hypersaline salt flat and the highest lithium reservoir on Earth. In addition to extreme temperatures and high UV irradiance, SdU has high concentrations of chaotropic salts which can be important factors in controlling microbial diversity. Here, for the first time we characterize the viral diversity of this hypersaline environment during the two seasons, as well as the physicochemical characteristics and the prokaryotic communities of the analyzed samples. Most of the selected samples showed a peculiar physicochemical composition and prokaryotic diversity, mostly different from each other even for samples from locations in close proximity or the same season. In contrast to most hypersaline systems Bacteria frequently outnumbered Archaea. Furthermore, an outstanding percentage of members of Salinibacter sp., likely a species different from the cosmopolitan Salinibacter ruber, was obtained in most of the samples. Viral communities displayed the morphologies normally found in hypersaline environments. Two seasonal samples were chosen for an detailed metagenomic analysis of the viral assemblage. Both viral communities shared common sequences but were dominated by sample-specific viruses, mirroring the differences also observed in physicochemical and prokaryotic community composition. These metaviromes were distinct from those detected in other hypersaline systems analyzed to date.

\section{Introduction}

Salar de Uyuni (SdU), with a surface of approximately 10,580 square kilometers is a hypersaline environment that contains the largest evaporitic basin and the largest estimated 
lithium reservoir on Earth (Kesler et al., 2012). It is located on the Andean Plateau in the Potosi region of Bolivia at 3,650 m. In addition to the high ionic concentration of the brines, close to saturation, the system is exposed, due to its location, to additional extreme conditions such as temperature fluctuations, high degree of UV irradiation and high albedo (Reuder et al., 2007). The surface of SdU is dry most of the year except for the occasional rains, which occur in the wet season, depending on the year, from December to April, that transform SdU into a transient hypersaline lake (Haferburg et al., 2017). Saturated salt brines can be found under the salt crust in most of the SdU and are used in the industrial part of the lake for the production of lithium. Unusually for salt lake brines, SdU has high concentrations of $\mathrm{MgCl}_{2}$, $\mathrm{LiCl}$ and $\mathrm{NaBr}$; all strong chaotropic stressors able to inhibit cellular growth (Hallsworth et al., 2007; Williams and Hallsworth, 2009; Cray et al., 2013; Ball and Hallsworth, 2015). Two recent independent studies based on 16S rRNA gene sequencing have shown that the archaeal community of SdU is dominated by Halonotius belonging to the Halobacteriaceae family (Haferburg et al., 2017; Rubin et al., 2017), and to a lesser extent by members of the Nanohaloarchaeota phylum and Thermoplasmata (Rubin et al., 2017). Surprisingly, Haloquadratum walsbyi, one of the most abundant and dominant microbes in coastal hypersaline systems (Santos et al., 2010) was not detected (Haferburg et al., 2017; Rubin et al., 2017), likely because of the unusual chemical composition of the SdU (Rubin et al., 2017). The SdU bacterial community was dominated by the extremely halophilic bacterium Salinibacter spp. along with other minor genera, such as Pedobacter and Alkalitalea (Rubin et al., 2017). These preliminary studies also showed a strong correlation between $\mathrm{Mg}^{2+}$ 
concentrations and prokaryotic diversity as well as community composition of SdU (Rubin et al., 2017).

Although viruses are the main biotic factors controlling the structure of hypersaline microbial communities due to the lack of other major predators (Santos et al., 2012; Normand et al., 2015), they have been largely underappreciated for years until the advent of metagenomics (Santos et al., 2007; Santos et al., 2010; Sime-Ngando, 2014; Pradeep, R., et al., 2016). Overall, viruses in hypersaline systems present the highest concentration of virus-like particles (VLP) reported in aquatic ecosystems (up to 100 times more than in fresh or marine water) with viral concentrations up to $10^{10} \mathrm{VLP} / \mathrm{ml}$ (Santos et al., 2012). The study of viral communities and virus-host interactions in extreme environments is essential to understanding the co-evolution and diversification of microbial populations (Hurwitz et al., 2014; Brum et al., 2015).

Here, we report the analysis of the prokaryotic communities of seven samples (three from the dry/cold and four for the wet/warm season) from SdU that had been collected both from a natural non-anthropogenic area and from near the lithium-industrial exploitation area. Overall, samples showed a high heterogeneity in physico-chemical composition that was quite site-specific, albeit wet/warm samples segregated from those collected at the dry/cold season. 16S rRNA gene data showed that prokaryotic community structure was different in most of the selected sampling sites, specifically for Bacteria, and was dominated by an unusual enrichment in members of the genus Salinibacter (up to $98 \%$ of the retrieved bacterial sequences in one of the samples) frequently with Halorubrum as the most commonly recovered archaeal genus. In two sampling sites in which these genera were rare 
( $<2 \%$ of $16 \mathrm{~S}$ rRNA gene data), they were almost entirely replaced by other dominant microbes, suggesting a taxonomic partitioning (i.e. separation of taxons). Since a strong physico-chemical and prokaryotic diversity heterogeneity was observed and, given that within the area impacted by anthropogenic activity several factors related with the lithiumindustrial activity cannot be easily managed, we sought to investigate the viral diversity from the undisturbed area by means of viral metagenomics. Viruses from SdU, although morphological similar to those from other hypersaline environments, were considerable different to previously described haloviruses. Viral communities from two close sampling sites were indeed very different and viral assembled genomes did not resemble previously described haloviruses infecting the abundant Salinibacter ruber and other known cosmopolitan microbes in hypersaline systems. Thus, data indicated that the singularity of the SdU system likely imposes certain environmental and physico-chemical constraints that drive the community structures of viruses and microbial hosts differently.

\section{Results and Discussion}

\section{Physico-chemical characterization of the samples}

A total of seven samples were collected, five from the industrial area dedicated to lithium exploitation and two from a natural, undisturbed area (Fig. 1A). All the brines from the lithium-industrial area were obtained from wells (i11), prospecting trenches (Zi7 and i3) and from an area of the lake that is always covered with water independently of the season (Zi18 and i16). Three of these samples were taken during the dry-cold season (Zn5, Zi7 and Zi18) while the other four at the wet-warm season (i3, i11, i16 and Zn24) (Table 1). Samples Zn5 
and Zn24, from the undisturbed area, were collected from natural holes in the salt crust, 50 km away from the lithium-exploitation area, named “Ojos del Salar”, with direct access to the underground brines (at 20-30 cm depth).

Physico-chemical characterization of samples (Table 1) showed that, as expected, the temperature of the samples collected in the dry season was much lower than the temperature of the samples from the wet season (Table 1). A high variability in the redox potential was detected among different samples and different seasons, either from the industrial and undisturbed areas, while water activity was less variable. Chemical analyses confirmed the high concentrations in SdU samples of $\mathrm{MgCl}_{2}, \mathrm{LiCl}$ and $\mathrm{NaBr}$, all strong chaotropic agents, compared to other previously described solar salterns (Di Meglio et al., 2016; Mora-Ruiz et al., 2018). A principal component analysis (PCA) considering all the environmental variables showed a separation between samples from the dry/cold and wet/warm seasons, indicating that seasonal conditions have a strong influence on the segregation of the samples (Fig. 1B, Supporting Information Table S1). This correlation agreed with the seasonal differences detected for the chaotropic ions $\mathrm{Li}^{+}, \mathrm{Mg}^{2+}$ and $\mathrm{Br}^{-}$which reached higher concentrations in the dry/cold samples (Table 1). Indeed, the first component in the PCA (Fig. 1B), which correlated negatively with water activity and positively with the concentrations of $\mathrm{Mg}^{2+}, \mathrm{Li}^{+}$, $\mathrm{K}^{+}, \mathrm{Br}^{-}$and S (Supporting Information Table S1), clearly separated the dry/cold samples from wet/warm samples. As previously reported (Rubin et al., 2017) the concentrations of $\mathrm{Na}^{+}$and $\mathrm{Cl}^{-}$in SdU were rather stable. Remarkably, PCA also showed a significant dispersion of samples within the same season indicating that there is a much higher heterogeneity in physico-chemical composition in the different sampling sites (Fig. 1B) than previously 
thought. See for instance, samples i3 and i16, very close to each other and both from the industrial area, with highly contrasting physico-chemical composition regarding redox potential (-230 and 220, respectively), $\mathrm{Li}^{+}$or $\mathrm{Mg}^{2+}$ (Table 1 and Fig. 1B).

\section{Microbial and viral abundances}

DAPI counting showed that cell abundances range from $2.6 \times 10^{5}$ to $4 \times 10^{7}$ cells $/ \mathrm{mL}$ (Table 1 ), with most of the samples within the ranges of cell density commonly encountered in previously describe solar salterns or hypersaline systems (i.e in the $10^{6}-10^{7}$ range; Di Meglio et al., 2016; Maturrano et al., 2006). Surprisingly, in five out the seven samples analyzed, detected Bacteria outnumbered Archaea (Table 1), in contrast with what has been observed in many salterns (Santos et al., 2010, 2012; Di Meglio et al., 2016), suggesting that the microbial structure of SdU is unique.

The number of eukaryotic cells was extremely low (less than $100 \mathrm{cell} / \mathrm{mL}$ ) in all the sampled brines. The proportion of prokaryotic cells detectable by fluorescence in situ hybridization ranged from 4.8 to $39.8 \%$, which is considerably lower than what has been detected in other hypersaline environments (Gomariz et al., 2015). This low detectability can be due either to failure in the permeabilization steps or to a low number of ribosomes inside the cells (Amann and Fuchs, 2008; Stahl and Amann, 1991). The first hypothesis does not seem plausible since this protocol has been successfully applied to other hypersaline samples harboring similar microbes (see below). The number of 16S rRNA molecules (i.e ribosomes) per cell required to detect a bacterial cell using CARD-FISH is around a few dozens, depending on the sample conditions (Hoshino et al., 2008), which is very low even for environmental bacteria (Amann 
and Fuchs, 2008). The low detectability levels in SdU samples might therefore indicate that whereas some halophiles thrive at salt saturation (Lee at al., 2018), stress constrains the metabolic activity of SdU microbial community.

Virus concentrations varied less than cell numbers among samples, from $1.55 \times 10^{7}$ to 2.23 $\times 10^{8}$ VLPs/mL (Table 1, Fig. 2A). Virus to cell ratios were between 0.51 and 122.5 and did not show any clear trend with regard to the abundance of Archaea, Bacteria or total cells. Transmission electron microscopy revealed four different viral morphologies: lemon shaped, spherical, head-tail and filaments (Fig. 2B). These viral morphotypes corresponded to the classical distribution present in hypersaline environments (Garcia-Heredia et al., 2012; Santos et al., 2012) with a predominance of spherical viral morphologies in all samples, followed by lemon shaped and head-tail morphologies (Fig. 2C), with the exception of sample Zi18, which showed higher proportion of lemon-shaped morphologies (Fig. 2C). The lemon-shaped viruses have usually been considered to infect Archaea (Atanasova et al., 2015), while head tail and spherical morphologies have been correlated both with bacterial and archaeal hosts (Atanasova et al., 2015). Regarding viral morphologies, wet/warm season samples i16, Zn5 and i3, showed more diverse types of virions, with five out of the seven described morphologies (Fig. 2B).

\section{Characterization of the prokaryotic diversity}

Prokaryotic diversity was characterized by means of high-throughput partial sequencing of 16S rRNA gene directly amplified from environmental DNA. After quality filtration and singletons removal, a total of 369,517 reads and 2,051 OTUs (see Experimental Procedures) 
for Bacteria and 490,526 reads and 352 OTUs for Archaea were obtained from the three dry season samples. Likewise, a total of 529,416 reads and 4,041 OTUs for Bacteria and 497,763 reads and 825 OTUs for Archaea were obtained from the wet season four samples. Thus, at the OTU level bacterial assemblages were more diverse than archaeal (Fig. S1).

Overall, UniFrac analyses of samples indicated that the variation of bacterial diversity among samples was larger than that of the Archaea (Fig. 3), even for samples taken during the same season. Regarding Bacteria, there is a significant heterogeneity in diversity structure among samples regardless the season and sampling domain (industrial vs natural). In the case of Archaea, observed diversity was in general more homogenous among samples, except samples Zi7 and i11 that harboured more divergent communities.

Regarding the composition of the prokaryotic communities, most frequently retrieved sequences corresponded to widely distributed, readily culturable genera of extremely halophilic organisms, namely the bacterium Salinibacter spp. and the archaeon Halorubrum spp. (Supplementary Dataset 1) (Ventosa et al., 2015; Rubin et al., 2017). Within the Bacteria, in four out of seven samples (i.e., Zi18, Zn24, Zn5, and i3) Salinibacter sp. clearly dominated, with an unusual abundance (up to $97.8 \%$ of the retrieved sequences; Supplementary Dataset 1). Fine comparison of 16S rRNA gene sequences assigned to Salinibacter genus, indicated that other Salinibacter species different than the known S. ruber populated and dominated the SdU system since nearly all sequence reads (95\% of total bacterial reads) had $<95 \%$ of identity with S. ruber (Fig. S2). Intriguingly, in two of the studied samples, Salinibacter spp. was rare $(<2 \%)$, and in turn, was replaced by other dominant bacterial genera (Supplementary Dataset 1). In the case of sample i11 this was 
Halothiobacillus (71.5\%), while in i16, Halomonas dominated the bacterial community (52\%). Similarly, within the Archaea, Halorubrum dominated the community in most of the samples, except samples i11 and Zi18, in which it was almost entirely replaced by a member of the MSBL1 group and the Methanomicrobia, respectively (Supplementary Dataset 1). The replacement of Salinibacter and Halorubrum by other dominant microbes suggests a taxonomic partitioning of the community in these samples. Members of the archaeal MSBL1 have been detected in sediments of coastal salterns (López-López et al., 2010) and in the deep sea brine pools, some of them with very high concentrations of $\mathrm{MgCl}_{2}$ (Siam et al., 2012; Yakimov et al., 2013; Mwirichia et al., 2016). It should be mentioned that in samples dominated by Salinibacter, the archaeal Halorubrum is also the dominating genus. Furthermore, the difference in bacterial and archaeal diversity detected in most of the analyzed samples was remarkable even though they were from sampling sites in close proximity and during the same season (Fig. 3). On the other side, samples i3 and Zn24 which are from the same season but from distant locations and with opposite redox potential share a similar bacterial diversity (Table 1, Fig. 1, Supplementary Dataset 1, and Fig. 3).

Finally, rarefaction curves for OTUs indicated that for both Bacteria and Archaea, dry/cold samples harbored less diversity than wet/warm samples (Fig. S1). The Shannon indexes (Supporting Information Table S2) were in good agreement with the rarefaction results and were in most samples typical of high diversity systems (i.e. above 3; May, 1975).

\section{Metagenomic characterization of the virus assemblages of the natural, undisturbed area}


Since a strong heterogeneity in samples was observed in microbial community structure and physico-chemical composition and given that several uncontrolled factors directly related with the Li-industrial activity can hinder the interpretation of metagenomic outcomes from samples taken within the industrial area, we sought to investigate the viral diversity in the undisturbed natural area. Samples Zn5 and Zn24, which were free of anthropogenic effects (Fig. 1A), were chosen for an in-depth analysis of their viral assemblages. In addition, these samples represented both seasons, corresponded to very close locations, and encompassed a wide range of physico-chemical conditions (Table 1).

Concerning these samples, the difference in bacterial diversity detected between them should be noted (Supplementary Dataset 1). While in Zn24 (wet/warm season), members of the genus Salinibacter accounted for most of the bacterial diversity (76\%), in Zn5 (dry/cold season), although Salinibacter was also present (but with a much lower percentage, 26\%), most of the detected diversity corresponded to strict or facultative anaerobic microorganisms such as Arhodomonas (26\%), Halorhodospira (5.9\%), Desulfovermiculus (2.5\%), Thiohalorhabdus (2.5\%) and Halanaerobium (1.1\%) which were either absent or present only in very low numbers in sample Zn24. These diversity differences agree with the reported redox potential values for these samples, negative and reducing for Zn5 and very positive and oxidant for Zn24.

The overall characteristics of the obtained viral metagenomes (hereinafter, metaviromes) are shown in Supporting Information Table S3. A total of 0.7 and 0.8 Gbp were sequenced for Zn5 and Zn24, respectively, and both delivered very high quality reads. Nonpareil analysis (Rodriguez-R and Konstantinidis, 2014) indicated that, in both cases, viral diversity was low 
(Supporting Information Fig. S3). Sequencing coverage values were around 60 and 50\%, for Zn5 and Zn24, respectively. Sequencing coverage above $60 \%$ have been recommended for obtaining meaningful, unbiased biological conclusions from metagenomes as well as avoiding the comparison of data sets with extreme differences in coverage (for example, >2fold) (Rodriguez-R and Konstantinidis, 2014). Therefore, despite the fact that the coverage of Zn24 metavirome is a bit lower than recommended, our data can be considered of enough quality for further analyses. Presence of $16 \mathrm{~S}$ rRNA genes in the SdU metaviromes was insignificant and far below the reported thresholds for metaviromes (Roux et al., 2013), as expected from the lack of amplification products obtained when viral DNA was submitted to PCR using bacterial 16S rRNA gene specific primers (see below). In good agreement, optical and electron microscopy confirmed the presence of viruses and the lack of cells in viral purified fractions from samples.

The average GC content of Zn5 and Zn24 metaviromes was 50.7 and 54.4\%, respectively (Supporting Information Fig. S4). The GC content distribution presented a unimodal curve and the majority of the reads for both metaviromes were distributed between 45 and 61\% GC content, the normal range previously described for viral and cellular metagenomes from other hypersaline environments (Ghai et al., 2010; Santos et al., 2010), although in these environments, the GC distribution was bimodal. Overall, the GC content of viruses and hosts tends to correlate; although phages are on average 4\% poorer in GC than their hosts (Santos et al., 2010; Crits-Christoph et al., 2016). Although 16S rRNA gene sequencing data does not allow us to infer GC content of the putative hosts in the system, we can use the GC content of the corresponding closest described microbes as a proxy. Thus, it seems reasonable to assume 
that the small peak around $45 \%$ in Supporting Information Fig. S4 could correspond to viruses infecting low GC hosts, such as Nanohaloarcheaota, which were detected in the prokaryotic communities, albeit at low proportion. The rest of the viral community, with higher GC values, could correspond to viruses infecting hosts with high GC content, such as Salinibacter spp., Arhodomonas spp., and different members of the Halobacteriales (with GC contents from 60 to $70 \%$ approximately), that were the most frequently retrieved groups in the 16S rRNA gene analysis.

The metagenomic analysis “all versus all” revealed that the sample Zn5 shared $44 \%$ of its nucleotides with Zn24, while sample Zn24 shares only 34\% with Zn5 (Fig. 4A). In other words, both viral communities share common viral sequences but are mainly composed of sample specific viruses probably due to the microbial community differences detected between the two samples. Around $10 \%$ of the metavirome reads could be assembled into contigs (see Experimental Procedures), with more than 10 contigs larger than $5 \mathrm{~kb}$ in each metavirome (Supporting Information Table S3). The low proportion of assembled reads in viromes has been related with high microdiversity of viral populations in some natural samples, which hampers viral genome assembly even from abundant viruses (MartinezHernandez et al., 2017; Roux et al., 2017). This is likely the case of SdU viral communities, as discussed below more thoroughly.

According to Metavir (see Experimental Procedures), all viruses classified in Zn5 and Zn24 were dsDNA, with predominance of contigs associated to Caudovirus followed by unclassified virus (Supporting Information Fig. S5). These data agree with the morphological observations made with TEM, in which the largest proportion corresponds to head-tail virus 
and is in line with that observed in other hypersaline environments (Brum and Steward, 2010). Despite the significantly high abundance of lemon shaped viruses in SdU, the absence of contigs associated with known lemon shaped virus genomes from other hypersaline systems only underlines the vast genetic diversity that probably is found and 'hidden' within the same lemon-shaped morphology, as also observed for dsDNA bacteriophages with typical icosahedral head-tail shape. For instance, to date only one fusiform (i.e. lemon shaped) virus has been isolated and sequenced (Atanasova et al., 2015).

When SdU metaviromes were compared with those from other hypersaline environments using either unassembled or assembled data (Fig. 5, Supporting Information Fig. S6 and Supporting Information Table S4), SdU metaviromes clustered together and apart from the rest of viral assemblages (from low, medium and high salt environments) (Fig. 5). Furthermore, the rarefaction curves performed using SdU and public hypersaline metaviromes available at the Metavir platform (Supporting Information Fig. S7) showed that Zn24 is richer than $\mathrm{Zn5}$, in agreement the nonpareil results and parallels the rarefaction curves from the corresponding prokaryotic communities (Supporting Information Fig. S1). Furthermore, these rarefaction curves indicate that SdU metaviromes are more diverse than the rest of high salinity viral assemblages included in the analysis (Supporting Information Fig. S7).

Regarding gene annotation of SdU metaviromes, we have been able to assign known genetic functions to approximately $8 \%$ of the detected genes in the assembled metaviromes. The remaining 92\% were annotated as "hypothetical proteins”. This high proportion of new genes is in line with what is found in most environmental hypersaline metaviromes (Villamor et al., 
2018) and is likely due to the considerable genetic novelty encoded by viral genomes, frequently referred to as “viral dark matter” (Hurwitz and Sullivan, 2013; Roux, et al., 2015). Although the most abundant functional categories (i. e. replication, recombination, DNA repair, phage mobility and transcription) are conserved in the two metaviromes, the distribution of genes with known function showed important differences. As shown in Figure 4C, except for replicative DNA helicase, the most abundant genes were different for each metavirome. These differences at the annotation level again indicated that viral assemblages are considerably different in both samples, most probably as a consequence of the different microbial diversity detected in both samples as well as the seasonal changes and peculiarities of physico-chemical composition in each sampling site.

Since viral contigs assembled from metaviromes represent partial or complete viral genomes which are abundant in the system (Angly et al., 2006), SdU viral genome fragments larger than $5 \mathrm{~Kb}$ from Zn5 and Zn24 metaviromes were further characterized in depth. First, abundances of these viruses were calculated in both metaviromes as described in Experimental Procedures. Zn5 large contigs represented $0.1556 \%$ of Zn5 total metavirome (Supporting Information Fig. S8) while they accounted for $0.074 \%$ of the Zn24 total reads. Conversely, Zn24 large viral contigs constituted $0.5 \%$ and $0.126 \%$ of the Zn24 and Zn5 total reads, respectively (Fig. 4B and Supporting Information Fig. S8). Furthermore, viral metagenomic fragment recruitment data (Fig. 4B and Supporting Information Fig. S8) indicated that most contigs were present only in their metavirome of origin (e.g. most Zn 24 contigs were only detected in Zn 24 metavirome). In addition, some contigs were considerably microdiverse (see, for instance the contig labeled with an asterisk in Fig. 4B). 
Indeed, although this contig from Zn5 recruited reads from Zn24, it could not be assembled in Zn24 likely due to its high microdiversity. As mentioned above, this is a problem also encountered by others when assembling metaviromes (Martinez-Hernandez et al., 2017).

\section{In silico virus-host association}

Although speculative, different genomic signature traits can be used as proxy to assign viruses to host by metagenomics, such as GC content, usage codon, di- and tetra-nucleotide frequencies, tRNA or CRISPR proto-spacer matches (Santos et al., 2010; Garcia-Heredia et al., 2012; Martínez-García et al., 2014; Roux et al., 2017). Here, in viral samples Zn4 and Zn25, the prokaryotic genomes corresponding to the most frequently recovered $16 \mathrm{~S}$ rRNA gene sequences (i.e. the most likely hosts in the system) were used as proxies to find putative virus-host pairs with the retrieved viral genomes $(>5 \mathrm{~Kb})$ from these samples. Codon usage analyses indicated (Supporting information Fig. S9) that $\approx 24$ viral contigs out of 50 were more related and closer to high GC content hosts like the archaea Halorubrum and Halobacterium, or bacteria like Salinibacter; each present and abundant in the prokaryotic community (Supplementary Dataset 1). However, viral assignment was not sufficiently robust to identify clear virus-host assignment pairs within high GC content hosts, since for instance GC content values of Halorubrum and Salinibacter are very similar. Nevertheless, data showed that some viral contigs had a codon usage more similar to that of low GC Nanohaloarcheaota, which were detected in both samples (see Supplementary Dataset 1). Diand tetranucleotide frequency analyses showed similar results (data not shown). Finally, although tRNA and CRISPR proto-spacer match search have been successfully used to assign viruses to hosts in hypersaline environments (Santos et al., 2010; Garcia-Heredia et al., 
2012), these approaches did not yield clear-cut results with SdU metaviromes (data not shown).

\section{Concluding remarks}

Salar de Uyuni is a large heterogeneous hypersaline environment that hosts an also rather heterogenous prokaryotic community in the brines under the salt crust. Members of Salinibacter and Halorubrum genera were detected in most of the samples, but the overall diversity of Archaea and, even more so Bacteria, was site-specific since each site was dominated by a few specific genera, likely mirroring the contrasting physico-chemical composition. Viral assemblages of this chaotropic system, characterized here for the first time, harbored the morphologies normally found in hypersaline environments worldwide. However, metagenomic analyses indicated that viruses in Salar de Uyuni, in spite of the intra sample diversity, clustered together an apart from other viral communities from hypersaline systems worldwide. Further studies should be devoted to clarify the effect that different environmental variables have on the host-virus interactions and as drivers of the peculiar microbial community structures unveiled by this study for this unique hypersaline ecosystem.

\section{Experimental procedures}

\section{Collection of samples at Salar de Uyuni (SdU)}

Water samples (between 200 and $500 \mathrm{ml}$ ) were taken from seven sampling stations at different locations of SdU (Supporting Information Table S5), three during the dry/cool season (July 2013) and four from the wet/warm season (February 2014). Samples were kept 
at $4^{\circ} \mathrm{C}$ for three days until filtration through a $0.2 \mu \mathrm{m}$ pore-size polycarbonate membranes (Millipore) to retain prokaryotic and eukaryotic cells (Supporting Information Table S5). Cell free-filtrates were kept at $4{ }^{\circ} \mathrm{C}$ until virus were concentrated and characterized as described below.

\section{Physico-chemical characterization}

Temperature, $\mathrm{pH}$, redox potential and dissolved $\mathrm{O}_{2}$ were measured in situ with a multiprobemeter. Water activity was measured using a Novasina Lab MasterRochtronic HP23-AW water activity meter calibrated to five points ( $a w=0.325,0.595,0.755,0.845$ and 0.935 ) using saturated calibration standards $\left(\mathrm{MgCl}_{2}, \mathrm{NH}_{4} \mathrm{NO}_{3}, \mathrm{NaCl}, \mathrm{KCl}\right.$ and $\mathrm{KHPO}_{4}$ respectively) prepared as described by Winston and Bates (1960). $10 \mathrm{ml}$ of each sample was measured in triplicate. Elemental analysis was performed with TXRF (Extra II) and ICP-MS (ELAN60000 PE-Sciex) instruments and ion chromatography with an IC Dionex DX-600 apparatus. Finally, the salinity concentration was measured using an optical refractometer (Sper Scientific) in the laboratory.

\section{Prokaryote abundance and fluorescence in situ hybridization}

Water samples were fixed with formaldehyde (4\% (v/v), final concentration). Fixed samples were filtered using black polycarbonate filters (0.2 $\mu \mathrm{m}$ pore size, Millipore). In situ hybridizations with horseradish peroxidase (HRP)-labeled probes followed by the catalyzed deposition of fluorescently labeled tyramide were carried out as described before (Pernthaler et al., 2004). Briefly, after filtration of samples, filters were embedded in sterile $0.2 \%(\mathrm{w} / \mathrm{v})$ agarose to avoid the detachment of cells. Then filters were treated with a solution of 
hydrogen peroxide in methanol for inactivation of endogenous peroxidases, and with lysozyme and proteinase $\mathrm{K}$, for permeabilization of cells. The filters were washed with absolute ethanol and sections of each filter were cut to use and the remaining filter stored at $-20^{\circ} \mathrm{C}$. Filters sections were incubated with the hybridization buffer, washed, incubated with the CARD solution and washed again. Probe mix EUB338 I-III (Amann et al., 1990; Daims et al., 1999) was used to target members of the domain Bacteria (formamide concentration of 35\% (v/v) in hybridization buffer) and the general probe ARCH915 (Stahl and Amann, 1991) was used for targeting members of Archaea (formamide concentration of $20 \%(\mathrm{v} / \mathrm{v})$ in hybridization buffer). Probe NON338 (Wallner et al., 1993), a nonsense probe was used as negative control probe to evaluate non-specific probe binding (formamide concentration of 0\% (v/v)). Tyramide-Alexa Fluor 488 and tyramide-Alexa Fluor 594 were used in the CARD solution. Probes and fluorophores were purchased from Biomers (Ulm, Germany).

Finally, the filter sections were mounted on slides with a 4:1 mix of Citifluor: Vectashield and with DAPI (4', 6-diamidino-2-phenylindole) (Thermo-Fisher) which stains DNA molecules. The mounting medium Citifluor (Citifluor Ltd, UK) and Vectashield (Vector Laboratories) were used to decrease the rate of fluorescence fading from the preparations. Filters stained with DAPI and dually hybridized with bacteria and archaea probes were examined under an epifluorescence microscope (Axioplan 2, Zeiss).

\section{Viral count and transmission electron microscopy of viruses}

Fluorescent SYBR-Gold staining was carried out as Boujelben et al. (2012) using $20 \mu \mathrm{l}$ of sample fixed with formaldehyde (4\% final concentration $(\mathrm{v} / \mathrm{v})$ ) that was filtered through 0.02 
$\mu \mathrm{m}$ Anodisc 25 Walkman $^{\circledR}$ filters. Viral particles were observed in epifluorescence microscopy Leica DM 4000B using a $100 \times$ fluorescence oil-immersion objective.

The viral morphologies were determined by transmission electron microscopy (TEM), in a Jeol JEM-2010 transmission electron microscope (JEOL Manufacturer, Tokyo, Japan). A total of 5 ul of each viral concentrate (see below in Viral DNA extraction protocol) were stained with 2\% uranyl acetate protocol previously described by Villamor et al., 2018.

\section{Principal component analysis (PCA)}

Principal component analysis (PCA) was performed by SPSS Statistics for Windows, Version 23 (https://www-01.ibm.com/support/docview.wss?uid=swg21476197) tool to determine the difference between samples based on Euclidean distance matrix of physicochemical parameters (anions and cations, salinity, $\mathrm{pH}$, conductivity, redox, dissolved $\mathrm{O}_{2}$ and temperature). PCA plot was carried out using version PASW stadistics data editor

\section{Viral DNA extraction and next generation sequencing}

Water samples were filtered by tangential flow filtration (TFF) to remove the cell fraction, the pure viral fraction of different volumes (200-500 ml) (Table 1) were concentrated through Vivaflow 200-PES system (initial volume to $20 \mathrm{ml}$ ) with $30 \mathrm{KDa}$ and re-concentrated to 500 $\mu \mathrm{l}$ by ultracentrifugation 185.000 Xg (Bekman Coulter ${ }^{\circledR}$, optima ${ }^{\mathrm{TM}}$ Max-XP ultracentrifuge), $4 \mathrm{~h}, 20^{\circ} \mathrm{C}$. Then, $50 \mu \mathrm{l}$ of ultracentrifuged sample was used to determine the viral genome sizes by pulsed field electrophoresis gel (PFGE). Viral DNA extraction was carried out as described previously (Santos et al., 2010) incubating low melting agarose inserts (plugs) with 
Turbo DNase (Ambion) before ESP treatment, to reduce cellular contamination. Cellular DNA contamination in the viral fraction was checked by PCR with DGGE archaeal primers (341F and 907 R) (Gomariz et al., 2015), including an inhibition control in which the viral DNA was mixed with Hqr. walsbyi DNA and used as template for PCR amplification. Sequencing of viral DNA extracted from plugs was performed using Illumina platform, Miseq Nextera XT 300x2 base pair (bp) paired-end run.

\section{Taxonomic analysis of prokaryotic communities}

Liquid samples were filtered through polycarbonate membranes $(0.2 \mu \mathrm{m}$ diameter; Millipore, USA). Total genomic DNA were extracted from those membranes using PowerSoil ${ }^{\circledR}$ DNA Isolation kit (MO BIO Laboratories, CA, USA). Total DNA was quantified with NanoDrop One/Onec UV-Vis Spectrophotometer (ThermoFisher) and stored at $-20^{\circ} \mathrm{C}$ until further analysis.

Small subunit ribosomal genes were amplified using different primers sets (Table S6). PCR reactions were performed as described before (Klindworth et al., 2013; Cruaud et al., 2014). Gel electrophoreses (1\% agarose Conda, Spain in 0.5X TBE buffer) were carried out to check the size and quality of PCR products. DNA concentrations were quantified by Qubit 2.0 fluorometer (Invitrogen). Library preparation and sequencing by Illumina MiSeq were made by Genomic Unit in Parque Científico de Madrid Foundation/FPCM (Madrid, Spain).

Quatily of reads was evaluated by means of FastQC software. PANDAseq Assembler was used for assembling forward and reverse reads and conversion in a fasta file (Bartram et al., 2011). Sequencing data were processed using Qiime software package version 1.9.0 
(Caporaso et al., 2010). High quality sequences were clustered into OTUs based on 94\% sequence similarity with UCLUST. The first sequence for each OTU was picked as the representative OTU, which were aligned using PYNAST (Caporaso et al., 2010). The taxonomic identity of each phylotype was determined using the SILVA_128_QIIME database (https://www.arb-silva.de/download/archive/qiime/) (Quast et al., 2012). OTU tables were filtered in order to extract the core of all these samples. Alpha diversity analysis was calculated using the OTU tables of each season. Beta diversity was analyzed from the OTU tables from all samples.

The identity distribution of Salinibacter 16S rRNA gene sequences was performed by BLASTn using Salinibacter ruber strain M31 16S rRNA gene (Peña et al., 2010) as database and the output was filtered by best_hit option (Rodriguez-R and Konstantinidis, 2016).

\section{Metavirome analyses}

Read quality was assessed and trimmed using PRINSEQ software (Schmieder and Edwards, 2011) and the resulting reads were joined by fq2a using the IDBA1.1.1 assembler (--merge -filter). Metagenomic assembly was done using IDBA 1.1.1 assembler with the “pre_correction” option (Peng et al., 2012).

The metaviromes were analyzed with nonpareil (Rodriguez-R and Konstantinidis, 2014) to estimate coverage and diversity of each sample. The reads of all metaviromes were compared reciprocally by BLASTn stand alone (applied thresholds: evalue $10^{-1}$ and $>70 \%$ coverage). Abundance of the obtained assembled viral contigs ( $>5 \mathrm{~kb})$ from each metavirome was determined using BLASTn with the same parameters indicated above. Then, the BLASTn 
output was filtered by best_hit option and read coverage $>70 \%$. Finally, recruitment plots were carried out by enveomics tool (Rodriguez-R and Konstantinidis, 2016) using enve.recplot 2 ( $\mathrm{R}$ stadistic pluging). Open reading frames (ORF) prediction and functional annotation were automatically done at JGI and Metavir platforms (Roux et al., 2011; Huntemann et al., 2014). In parallel, raw reads were annotated manually using nr and POG databases (ORF prediction by prodigal default parameters).

Our datasets were compared with metaviromes from hypersaline environments around the world (Rodriguez-Brito et al., 2010; Roux et al., 2016) using the BLAST based global comparison and clustering based rarefaction tools as implemented in the Metavir platform (Roux et al., 2011). The obtained multidimensional scaling plot (MDS) and tree were drawn with pvclust (Suzuki and Shimodaira, 2006) and vegan libraries , respectively

\section{In silico virus- host pair prediction}

Virus-host pair prediction was performed using viral contigs larger than 5kb, and most probable host genomes were chosen based on the 16S rRNA analyses (see above). Putative host genomes were downloaded from the NCBI "genome” public database (NCBI Resource Coordinators, 2016). To assign virus-host pairs, the codon usage was calculated for each of them with EMBOSS cusp tools (Garcia-Heredia et al., 2012; McWilliam et al., 2013) and multidimensional scaling (MDS) was computed based on Bray-Curtis dissimilarity index, calculated and drawn with the R 3.2.2 vegan package (Oksanen et al., 2007). 


\section{Sequence data}

Sequences of 16S rRNA gene have been deposited in European nucleotide archive (ENA) under project numbers PRJEB30835.

Raw sequence metaviromes are publicly available at the repository of Discovery Environment (Cyverse) through the following links:

https://de.cyverse.org/dl/d/CEAB6764-643B-455C-BC1D-942B2B3544C5/ZN5.fa and https://de.cyverse.org/dl/d/07D6620E-CC50-4C72-A53F-E700B990EA37/ZN24.fa

Assembled metaviromes have been deposited at IMG genome (JGI-IMG) under accession numbers IMG-ID 3300007238 (Zn24) and IMG-ID 3300007084 (Zn5).

\section{Acknowledgements}

This research was supported by the Spanish Ministry of Economy and Competitiveness projects CLG2015_66686-C3-3 (to JA) and CGL2015-66242-R (to RA), which were also supported with European Regional Development Fund (FEDER) funds. Authors want to thank the Gerencia Nacional de Recursos Evaporíticos, COMIBOL, Estado Plurinacional de Bolivia, for facilitating the acquisition of the samples and Professor J.E. Hallsworth for his 
critical comments to the manuscript. The authors state that there is no conflict of interests that could be perceived to bias their work.

\section{References}

Amann, R. and Fuchs, B.M. (2008) Single-cell identification in microbial communities by improved fluorescence in situ hybridization techniques. Nat. Rev. Microbiol. 6: 339348.

Amann, R.I., Binder, B.J., Olson, R.J., Chisholm, S.W., Devereux, R., and Stahl, D.A. (1990) Combination of 16S rRNA-targeted oligonucleotide probes with flow cytometry for analyzing mixed microbial populations. Appl. Environ. Microbiol. 56: 1919-25.

Angly, F.E., Felts, B., Breitbart, M., Salamon, P., Edwards, R.A., Carlson, C., et al. (2006) The Marine Viromes of Four Oceanic Regions. PLoS Biol. 4: e368.

Atanasova, N.S., Oksanen, H.M., and Bamford, D.H. (2015) Haloviruses of archaea, bacteria, and eukaryotes. Curr. Opin. Microbiol. 25: 40-48.

Ball, P. and Hallsworth, J.E. (2015) Water structure and chaotropicity: their uses, abuses and biological implications. Phys. Chem. Chem. Phys. 17: 8297-8305.

Bartram, A.K., Lynch, M.D.J., Stearns, J.C., Moreno-Hagelsieb, G., and Neufeld, J.D. (2011) Generation of multimillion-sequence 16S rRNA gene libraries from complex microbial communities by assembling paired-end illumina reads. Appl. Environ. Microbiol. 77: $3846-52$. 
Boujelben, I., Yarza, P., Almansa, C., Villamor, J., Maalej, S., Antón, J., and Santos, F. (2012) Virioplankton Community Structure in Tunisian Solar Salterns. Appl. Environ. Microbiol. 78: 7429-7437.

Brum, J.R., Ignacio-Espinoza, J.C., Roux, S., Doulcier, G., Acinas, S.G., Alberti, A., et al. (2015) Patterns and ecological drivers of ocean viral communities. Science. 348: 1261498

Brum, J.R. and Steward, G.F. (2010) Morphological Characterization of Viruses in the Stratified Water Column of Alkaline, Hypersaline Mono Lake. Microb. Ecol. 60: 636643.

Caporaso, J.G., Bittinger, K., Bushman, F.D., DeSantis, T.Z., Andersen, G.L., and Knight, R. (2010) PyNAST: a flexible tool for aligning sequences to a template alignment.

Bioinformatics 26: 266-267.

Caporaso, J.G., Kuczynski, J., Stombaugh, J., Bittinger, K., Bushman, F.D., Costello, E.K., et al. (2010) QIIME allows analysis of high-throughput community sequencing data. Nat. Methods 7: 335-336.

Cray, J.A., Bell, A.N.W., Bhaganna, P., Mswaka, A.Y., Timson, D.J., and Hallsworth, J.E. (2013) The biology of habitat dominance; can microbes behave as weeds? Microb. Biotechnol. 6: 453-492.

Crits-Christoph, A., Gelsinger, D.R., Ma, B., Wierzchos, J., Ravel, J., Davila, A., et al. (2016) Functional interactions of archaea, bacteria and viruses in a hypersaline endolithic 
community. Environ. Microbiol. 18: 2064-2077.

Cruaud, A., Gautier, M., Galan, M., Foucaud, J., Sauné, L., Genson, G., et al. (2014) Empirical Assessment of RAD Sequencing for Interspecific Phylogeny. Mol. Biol. Evol. 31: $1272-1274$.

Daims, H., Brühl, A., Amann, R., Schleifer, K.-H., and Wagner, M. (1999) The Domainspecific Probe EUB338 is Insufficient for the Detection of all Bacteria: Development and Evaluation of a more Comprehensive Probe Set. Syst. Appl. Microbiol. 22: 434-444.

Garcia-Heredia, I., Martin-Cuadrado, A.-B., Mojica, F.J.M., Santos, F., Mira, A., Antón, J., and Rodriguez-Valera, F. (2012) Reconstructing viral genomes from the environment using fosmid clones: the case of haloviruses. PLoS One 7: e33802.

Ghai, R., Martin-Cuadrado, A.-B., Molto, A.G., Heredia, I.G., Cabrera, R., Martin, J., et al. (2010) Metagenome of the Mediterranean deep chlorophyll maximum studied by direct and fosmid library 454 pyrosequencing. ISME J. 4: 1154-1166.

Gomariz, M., Martínez-García, M., Santos, F., Rodriguez, F., Capella-Gutiérrez, S., Gabaldón, T., et al. (2015) From community approaches to single-cell genomics: the discovery of ubiquitous hyperhalophilic Bacteroidetes generalists. ISME J. 9: 16-31.

Haferburg, G., Gröning, J.A.D., Schmidt, N., Kummer, N.-A., Erquicia, J.C., and Schlömann, M. (2017) Microbial diversity of the hypersaline and lithium-rich Salar de Uyuni, Bolivia. Microbiol. Res. 199: 19-28.

Hallsworth, J.E., Yakimov, M.M., Golyshin, P.N., Gillion, J.L.M., D’Auria, G., de Lima 
Alves, F., et al. (2007) Limits of life in $\mathrm{MgCl}_{2}$-containing environments: chaotropicity defines the window. Environ. Microbiol. 9: 801-813.

Hoshino, T., Yilmaz, L.S., Noguera, D.R., Daims, H., and Wagner, M. (2008) Quantification of target molecules needed to detect microorganisms by fluorescence in situ hybridization (FISH) and catalyzed reporter deposition-FISH. Appl. Environ. Microbiol. 74: 5068-77.

Huntemann, A., Huntemann, M., Mavrommatis, K., Ivanova, N., Mikhailova, N., Ovchinnikova, G., et al. (2014) The JGI Pipeline for Annotation of Microbial Genomes and Metagenomes. Lawrence Berkeley National Laboratory Recent Work.

Hurwitz, B.L. and Sullivan, M.B. (2013) The Pacific Ocean virome (POV): a marine viral metagenomic dataset and associated protein clusters for quantitative viral ecology. PLoS One 8: e57355.

Hurwitz, B.L., Westveld, A.H., Brum, J.R., and Sullivan, M.B. (2014) Modeling ecological drivers in marine viral communities using comparative metagenomics and network analyses. Proc. Natl. Acad. Sci. U. S. A. 111: 10714-9.

Kesler, S.E., Gruber, P.W., Medina, P.A., Keoleian, G.A., Everson, M.P., and Wallington, T.J. (2012) Global lithium resources: Relative importance of pegmatite, brine and other deposits. Ore Geol. Rev. 48: 55-69.

Klindworth, A., Pruesse, E., Schweer, T., Peplies, J., Quast, C., Horn, M., and Glöckner, F.O. (2013) Evaluation of general 16S ribosomal RNA gene PCR primers for classical and 
next-generation sequencing-based diversity studies. Nucleic Acids Res. 41: e1-e1.

Lee CJD, McMullan PE, O’Kane CJ, Stevenson A, Santos IC, Roy C, Ghosh W, Mancinelli RL, Mormile MR, McMullan G, Banciu HL, Fares MA, Benison KC, Oren A, DyallSmith ML, H.J. (2018) NaCl-saturated brines are thermodynamically moderate, rather than extreme, microbial habitats. FEMS Microbiol. Rev. 42: 672-693.

López-López, A., Yarza, P., Richter, M., Suárez-Suárez, A., Antón, J., Niemann, H., and Rosselló-Móra, R. (2010) Extremely halophilic microbial communities in anaerobic sediments from a solar saltern. Environ. Microbiol. Rep. 2: 258-271.

Martínez-García, M., Santos, F., Moreno-Paz, M., Parro, V., and Antón, J. (2014) Unveiling viral-host interactions within the 'microbial dark matter'. Nat. Commun. 5: 4542.

Martinez-Hernandez, F., Fornas, O., Lluesma Gomez, M., Bolduc, B., de la Cruz Peña, M.J., Martínez, J.M., et al. (2017) Single-virus genomics reveals hidden cosmopolitan and abundant viruses. Nat. Commun. 8: 15892.

Maturrano, L., Santos, F., Rosselló-Mora, R., and Antón, J. (2006) Microbial diversity in Maras salterns, a hypersaline environment in the Peruvian Andes. Appl. Environ. Microbiol. 72: 3887-95.

May M. R. (1975) Patterns of species abundance and diversity. Ecol. Evol. Communities. 81120.

McWilliam, H., Li, W., Uludag, M., Squizzato, S., Park, Y.M., Buso, N., et al. (2013) Analysis Tool Web Services from the EMBL-EBI. Nucleic Acids Res. 41: W597-W600. 
Di Meglio, L., Santos, F., Gomariz, M., Almansa, C., López, C., Antón, J., and Nercessian, D. (2016) Seasonal dynamics of extremely halophilic microbial communities in three Argentinian salterns. FEMS Microbiol. Ecol. 92: fiw184.

Mora-Ruiz, M. de. R., Cifuentes, A., Font-Verdera, F., Pérez-Fernández, C., Farias, M.E., González, B., et al. (2018) Biogeographical patterns of bacterial and archaeal communities from distant hypersaline environments. Syst. Appl. Microbiol. 41: 139-150.

Mwirichia, R., Alam, I., Rashid, M., Vinu, M., Ba-Alawi, W., Anthony Kamau, A., et al. (2016) Metabolic traits of an uncultured archaeal lineage -MSBL1- from brine pools of the Red Sea. Sci. Rep. 6: 19181.

NCBI Resource Coordinators, N.R. (2016) Database resources of the National Center for Biotechnology Information. Nucleic Acids Res. 44: D7-19.

Normand, P., Duran, R., Le Roux, X., Morris, C., and Poggiale, J.-C. (2015) Biodiversity and Microbial Ecosystems Functioning. In, Environmental Microbiology: Fundamentals and Applications. Springer Netherlands, Dordrecht, pp. 261-291.

Oksanen, J., Kindt, R., Legendre, P., O ’hara, B., Henry, M., and Maintainer, H.S. (2007) The vegan Package Title Community Ecology Package. http://cran.r-project.org/, http://rforge.r-project.org/projects/vegan/.

Peña, A., Teeling, H., Huerta-Cepas, J., Santos, F., Yarza, P., Brito-Echeverría, J., et al. (2010) Fine-scale evolution: genomic, phenotypic and ecological differentiation in two coexisting Salinibacter ruber strains. ISME J. 4: 882-95. 
Peng, X., Garrett, R. a, and She, Q. (2012) Archaeal viruses--novel, diverse and enigmatic. Sci. China. Life Sci. 55: 422-33.

Pernthaler, A., Pernthaler, J., and Amann, R. (2004) Molecular Microbial Ecology Manual. Mol. Microb. Ecol. Man. 3: 711-726.

Pradeep Ram, A.S., Chaibi-Slouma, S., Keshri, J., Colombet, J., and Sime-Ngando, T. (2016) Functional Responses of Bacterioplankton Diversity and Metabolism to Experimental Bottom-Up and Top-Down Forcings. Microb. Ecol. 72: 347-358.

Quast, C., Pruesse, E., Yilmaz, P., Gerken, J., Schweer, T., Yarza, P., et al. (2012) The SILVA ribosomal RNA gene database project: improved data processing and web-based tools. Nucleic Acids Res. 41: D590-D596.

Reuder, J., Ghezzi, F., Palenque, E., Torrez, R., Andrade, M., and Zaratti, F. (2007) Investigations on the effect of high surface albedo on erythemally effective UV irradiance: Results of a campaign at the Salar de Uyuni, Bolivia. J. Photochem. Photobiol. B Biol. 87: 1-8.

Rodriguez-Brito, B., Li, L., Wegley, L., Furlan, M., Angly, F., Breitbart, M., et al. (2010) Viral and microbial community dynamics in four aquatic environments. ISME J. 4: 739751.

Rodriguez-R, L.M. and Konstantinidis, K.T. (2014) Estimating coverage in metagenomic data sets and why it matters. ISME J. 8: 2349-2351.

Rodriguez-R, L.M. and Konstantinidis, K.T. (2014) Nonpareil: A redundancy-based 
approach to assess the level of coverage in metagenomic datasets. Bioinformatics $\mathbf{3 0}$ : $629-635$.

Rodriguez-R, L.M. and Konstantinidis, K.T. (2016) The enveomics collection: a toolbox for specialized analyses of microbial genomes and metagenomes. PeerJ Prepr.

Roux, S., Brum, J.R., Dutilh, B.E., Sunagawa, S., Duhaime, M.B., Loy, A., et al. (2016) Ecogenomics and potential biogeochemical impacts of globally abundant ocean viruses. Nature 537: 689-693.

Roux, S., Chan, L.-K., Egan, R., Malmstrom, R.R., McMahon, K.D., and Sullivan, M.B. (2017) Ecogenomics of virophages and their giant virus hosts assessed through time series metagenomics. Nat. Commun. 8: 858.

Roux, S., Faubladier, M., Mahul, A., Paulhe, N., Debroas, D., Enault, F., et al. (2011)

Metavir : a web server dedicated to virome analysis . Bioinformatics 27: 3074-3075.

Roux, S., Hallam, S.J., Woyke, T., and Sullivan, M.B. (2015) Viral dark matter and virushost interactions resolved from publicly available microbial genomes. Elife 4: e08490.

Roux, S., Hawley, A.K., Torres Beltran, M., Scofield, M., Schwientek, P., Stepanauskas, R., et al. (2014) Ecology and evolution of viruses infecting uncultivated SUP05 bacteria as revealed by single-cell- and meta- genomics. Elife 3: e03125.

Roux, S., Krupovic, M., Debroas, D., Forterre, P., and Enault, F. (2013) Assessment of viral community functional potential from viral metagenomes may be hampered by contamination with cellular sequences. Open Biol. 3: 130160. 
Rubin, S.S., Marín, I., Gómez, M.J., Morales, E.A., Zekker, I., San Martín-Uriz, P., et al. (2017) Prokaryotic diversity and community composition in the Salar de Uyuni, a large scale, chaotropic salt flat. Environ. Microbiol. 19: 3745-3754.

Santos, F., Yarza, P., Parro, V., Briones, C., and Antón, J. (2010) The metavirome of a hypersaline environment. Environ. Microbiol. 12: 2965-76.

Santos, F., Yarza, P., Parro, V., Meseguer, I., Rosselló-Móra, R., and Antón, J. (2012) Culture-independent approaches for studying viruses from hypersaline environments. Appl. Environ. Microbiol. 78: 1635-43.

Schmieder, R. and Edwards, R. (2011) Quality control and preprocessing of metagenomic datasets. Bioinformatics 27: 863-864.

Siam, R., Mustafa, G.A., Sharaf, H., Moustafa, A., Ramadan, A.R., Antunes, A., et al. (2012) Unique Prokaryotic Consortia in Geochemically Distinct Sediments from Red Sea Atlantis II and Discovery Deep Brine Pools. PLoS One 7: e42872.

Sime-Ngando, T. (2014) Environmental bacteriophages: viruses of microbes in aquatic ecosystems. Front. Microbiol. 5: 355.

Stahl, D.A. and Amann, R. (1991) Development and Application of Nucleic Acid Probes. In, Nucleic Acid Techniques in Bacterial Systematics. pp.205-248.

Suzuki, R. and Shimodaira, H. (2006) Pvclust: an R package for assessing the uncertainty in hierarchical clustering. Bioinformatics 22: 1540-1542. 
Thingstad, T.F. (2000) Elements of a theory for the mechanisms controlling abundance, diversity, and biogeochemical role of lytic bacterial viruses in aquatic systems. Limnol. Oceanogr. 45: 1320-1328.

Ventosa, A., de la Haba, R.R., Sánchez-Porro, C., and Papke, R.T. (2015) Microbial diversity of hypersaline environments: a metagenomic approach. Curr. Opin. Microbiol. 25: 8087.

Villamor, J., Ramos-Barbero, M.D., González-Torres, P., Gabaldón, T., Rosselló-Móra, R., Meseguer, I., et al. (2018) Characterization of ecologically diverse viruses infecting cooccurring strains of cosmopolitan hyperhalophilic Bacteroidetes. ISME J. 12: 424-437.

Wallner, G., Amann, R., and Beisker, W. (1993) Optimizing fluorescent in situ hybridization with rRNA ntargettedeopigabes for flow cytometric identification of microorganisms. Cytometry 14: 136-143.

Williams, J.P. and Hallsworth, J.E. (2009) Limits of life in hostile environments: no barriers to biosphere function? Environ. Microbiol. 11: 3292-3308.

Yakimov, M.M., La Cono, V., Slepak, V.Z., La Spada, G., Arcadi, E., Messina, E., et al. (2013) Microbial life in the Lake Medee, the largest deep-sea salt-saturated formation. Sci. Rep. 3: 3554.

\section{Figure legends}

Figure 1. Salar de Uyuni location and sampling sites (A). Uyuni brines principal component analyses (PCA)(B). Input parameters for this analysis are shown in Table S1. The samples are 
represented with dark dots (Dry-cold samples) and withe dots (Wet-warm samples). The sequenced samples are marked with an asterisk (*).

Figure 2. SYBR gold-stained water samples from Zn5, Zn24 and i3 samples (A). Transmission electron micrographs showing the viral morphotypes detected in this study: lemon shaped and head tail viruses (panel I), head tail viruses (panels II, IV, V, VI), spherical (panel III), lemon shaped (panel IV), head tail (panel V), filamentous virus (panel VII), and head tail virus with unusual long tail (panel VIII) (B). Abundance of cells (squares), Bacteria (circles), Archaea (triangles) and viral morphologies (bars) in Uyuni brines; asterisks indicate analyzed metaviromes (C).

Figure 3. Prokaryotic communities, detected by Illumina sequencing, associated to the analyzed Uyuni samples clustered using coordinated analysis of the weighed UniFrac distance matrix. (A) Archaea. (B) Bacteria. The dot colors indicated the sampling seasons, dry cold period (blue) and wet warm (red).

Figure 4. Similarities and differences in Uyuni metaviromes Zn5 and Zn24. Comparison of reads (all versus all) by BLASTn (A). Abundance of the assembled contigs in the analyzed metaviromes. The contigs displaying highest diversity are labeled with asterisks. The inserted number refers to the proportion of reads recruited by the contigs (B). Profiles of the most abundant annotated functions in the metaviromes: DNA modification methylase (1), replicative DNA helicase (2), predicted ATPase involved in replication control Cdc46/Mcm family (3), terminase-like family (4), restriction endonuclease (5), phage-related protein (6), uncharacterized protein conserved in bacteria (7), site-specific DNA methylase (8), phage 
terminase large subunit (9), site-specific recombinase XerD (10), predicted transcriptional regulators (11), site-specific recombinases, DNA invertase Pin homologs (12), phage-related minor tail protein (13), 3'-phosphoadenosine 5'-phosphosulfate sulfotransferase (PAPS reductase)/FAD synthetase and related enzymes (14), phage Mu protein F like protein (15), DNA polymerase I - 3'-5' exonuclease and polymerase domains (16), phage terminase-like protein large subunit (17), predicted phage phi-C31 gp36 major capsid-like protein (18), glycosyltransferase (19), uncharacterized protein homolog of phage Mu protein gp30 (20), phage integrase family (21), reverse transcriptase (RNA-dependent DNA polymerase)(22), transcriptional regulator (23), uncharacterized conserved protein (24), outer membrane receptor proteins, mostly Fe transport (25), dehydrogenases with different specificities (related to short-chain alcohol dehydrogenases) (26), transcriptional regulators (27), integrase core domain (28), NAD-dependent aldehyde dehydrogenases (29), major Facilitator Superfamily (30), TonB-dependent Receptor Plug Domain (31), transposase (32), transposase and inactivated derivatives (33), ABC-type branched-chain amino acid transport systemsATPase component (34), cation/multidrug efflux pump (35), Acyl-CoA dehydrogenases (36), ABC-type sugar transport system, periplasmic component (37), Acyl-CoA synthetases (AMP-forming)/AMP-acid ligases II (38), ABC-type dipeptide/oligopeptide/nickel transport systems, permease components (39), response regulators consisting of a CheY-like receiver domain and a winged-helix DNA-binding domain (40) and protein kinase domain (41).

Figure 5. Principal component analyses (PCA) based on raw sequence (reads) distance by METAFAST comparison of Uyuni metaviromes with other hypersaline metaviromes available at METAVIR platform and unpublished metaviromes. Each metavirome is 
represented with a dot and the color intensity indicates the percentage of salinity (A). The table indicates the metavirome IDs in plot (B).

Figure S1. Alpha diversity rarefaction plots for (A) Archaea (B) Bacteria.

Figure S2. Graphic representation of identity distribution of Uyuni bacterial $16 \mathrm{~S}$ sequences based on BLASTn comparison with Salinibacter ruber M31 16S.

Figure S3. Diversity curves of Uyuni metaviromes calculated with the program Nonpareil. Zn5 metavirome (A) and Zn24 metavirome (B) diversity. In the bottom-right corner the coverage and diversity of each metavirome are shown.

Figure S4. GC content distribution of Uyuni metaviromes.

Figure S5. Taxonomic composition of Uyuni metaviromes performed by Metavir.

Figure S6. Principal component analyses (PCA) based on sequence similarity by BLAST comparison of Uyuni metaviromes with other hypersaline metaviromes available at the METAVIR platform (Rodriguez-Brito et al., 2010; Roux et al., 2016). Each metavirome is represented with a dot; the color intensity indicates the percentage of salinity.

Figure S7. Rarefraction curves of Uyuni metaviromes against public database of hypersaline metaviromes performed by Metavir.

Figure S8. Fragment recruitment analyses of contigs larger than $5 \mathrm{~Kb}$ of Uyuni metaviromes. BLASTn searches of the Zn5 (A) and Zn24 metavirome (B). 
Figure S9. Virus-host multidimensional scaling (MDS) based on codon use frequencies of viral and cell genomes. Viral draft genomes are represented with hexagons (blue for Zn 5 viral contigs and red in Zn 24 contigs) and the ellipses correspond to host genomes. 
Table 1. General characteristics of Uyuni brine samples: Geophysical, ionic and biological parameters.

\begin{tabular}{|c|c|c|c|c|c|c|c|c|c|c|c|c|c|c|c|c|c|c|c|c|c|}
\hline $\begin{array}{l}\text { Sample } \\
\text { ID }\end{array}$ & Sample site & $\begin{array}{l}\text { Sampling } \\
\text { period }\end{array}$ & $\begin{array}{c}\mathrm{T} \\
\left({ }^{\circ} \mathrm{C}\right)\end{array}$ & $\begin{array}{l}\text { Salinity } \\
(\%)\end{array}$ & $\begin{array}{l}\text { Conductivity } \\
(\mathrm{mV})\end{array}$ & $\mathrm{pH}$ & $\begin{array}{l}\text { Total } \\
\text { cells }\end{array}$ & Bacteria/ml & Archaea/ml & $\begin{array}{l}\mathrm{VLP} / \mathrm{ml} \\
0.22 \mu \mathrm{m}\end{array}$ & Eh (mv) & $\begin{array}{l}\text { Water } \\
\text { activity }\end{array}$ & $\mathrm{B}(\mathrm{g} / \mathrm{l})$ & $\begin{array}{l}\mathrm{Na} \\
(\mathrm{g} / \mathrm{l})\end{array}$ & $\begin{array}{l}\mathrm{Mg} \\
(\mathrm{g} / \mathrm{l})\end{array}$ & $\mathrm{Li}(\mathrm{g} / \mathrm{l})$ & $\mathrm{K}(\mathrm{g} / \mathrm{l})$ & $\mathrm{Ca}(\mathrm{g} / \mathrm{l}) \mathrm{B}$ & $\mathrm{Br}(\mathrm{g} / \mathrm{l})$ & $\mathrm{Cl}(\mathrm{g} / \mathrm{l})$ & $\mathrm{S}(\mathrm{g} / \mathrm{l})$ \\
\hline Zn 5 & Ojo del salar & Dry-cool & 5.1 & 32 & 222 & 6.8 & $3.6 \times 10^{7}$ & $\begin{array}{r}1.4 \times 10^{7} \\
(39 \%)\end{array}$ & $\begin{array}{r}3.2 \times 10^{5} \\
(0.9 \%)\end{array}$ & $2.23 \times 10^{8}$ & -19.00 & 0.68 & 1.06 & 147.36 & 36.56 & 1.83 & 31.70 & 0.25 & 0.74 & 347.24 & 3.74 \\
\hline$Z i 7$ & Trench \# 4 & Dry-cool & 7.0 & 36.4 & 200 & 6.4 & $1.8 \times 10^{7}$ & $\begin{array}{l}4.4 \times 10^{6} \\
(4.4 \%)\end{array}$ & bdl & $4.23 \times 10^{7}$ & -149.00 & 0.68 & 15.50 & 109.61 & 46.70 & 2.39 & 38.71 & 0.10 & 1.03 & 314.40 & 4.99 \\
\hline Zi 18 & $\begin{array}{l}\text { Right Salt } \\
\text { Towers }\end{array}$ & Dry-cool & 3.7 & 34.6 & 173 & 6.2 & $3.9 \times 10^{7}$ & $\begin{array}{l}1.9 \times 10^{6} \\
(6.3 \%)\end{array}$ & $\begin{array}{c}1.1 \times 10^{4} \\
(0.028 \%)\end{array}$ & $2 \times 10^{8}$ & -71.00 & 0.72 & 0.50 & 152.29 & 19.14 & 0.99 & 22.00 & 0.31 & 0.36 & 292.22 & 2.24 \\
\hline i 11 & Well \# 3 & $\begin{array}{l}\text { Wet- } \\
\text { warm }\end{array}$ & 17.2 & 30 & 227 & 6.4 & $2.6 \times 10^{5}$ & Bdl & $\begin{array}{l}3.4 \times 10^{4} \\
(13.1 \%)\end{array}$ & $1.55 \times 10^{7}$ & -31.00 & 0.85 & 0.19 & 178.43 & 3.34 & 0.01 & 5.75 & 1.40 & 0.02 & 272.10 & 0.64 \\
\hline ¡ 16 & $\begin{array}{l}\text { Right Salt } \\
\text { Towers }\end{array}$ & $\begin{array}{l}\text { Wet- } \\
\text { warm }\end{array}$ & 10.6 & 24 & 225 & 7.0 & $4 \times 10^{7}$ & $\begin{array}{c}1.3 \times 10^{7} \\
(32 \%)\end{array}$ & $\begin{array}{l}7.8 \times 10^{5} \\
(2.0 \%)\end{array}$ & $2.05 \times 10^{7}$ & 220.00 & 0.72 & 0.19 & 188.58 & 4.95 & 0.17 & 7.28 & 1.56 & 0.04 & 294.64 & 0.69 \\
\hline & Ojo del salar & $\begin{array}{l}\text { Wet- } \\
\text { warm }\end{array}$ & 23.0 & 34 & 225 & 6.5 & $1.1 \times 10^{6}$ & $\begin{array}{l}3.4 \times 10^{5} \\
(30.1 \%)\end{array}$ & $\begin{array}{c}8.9 \times 10^{4} \\
(7.9 \%)\end{array}$ & $1.10 \times 10^{8}$ & 210.00 & 0.74 & 0.45 & 218.39 & 13.06 & 0.52 & 17.45 & 0.68 & 0.11 & 369.39 & 1.55 \\
\hline
\end{tabular}




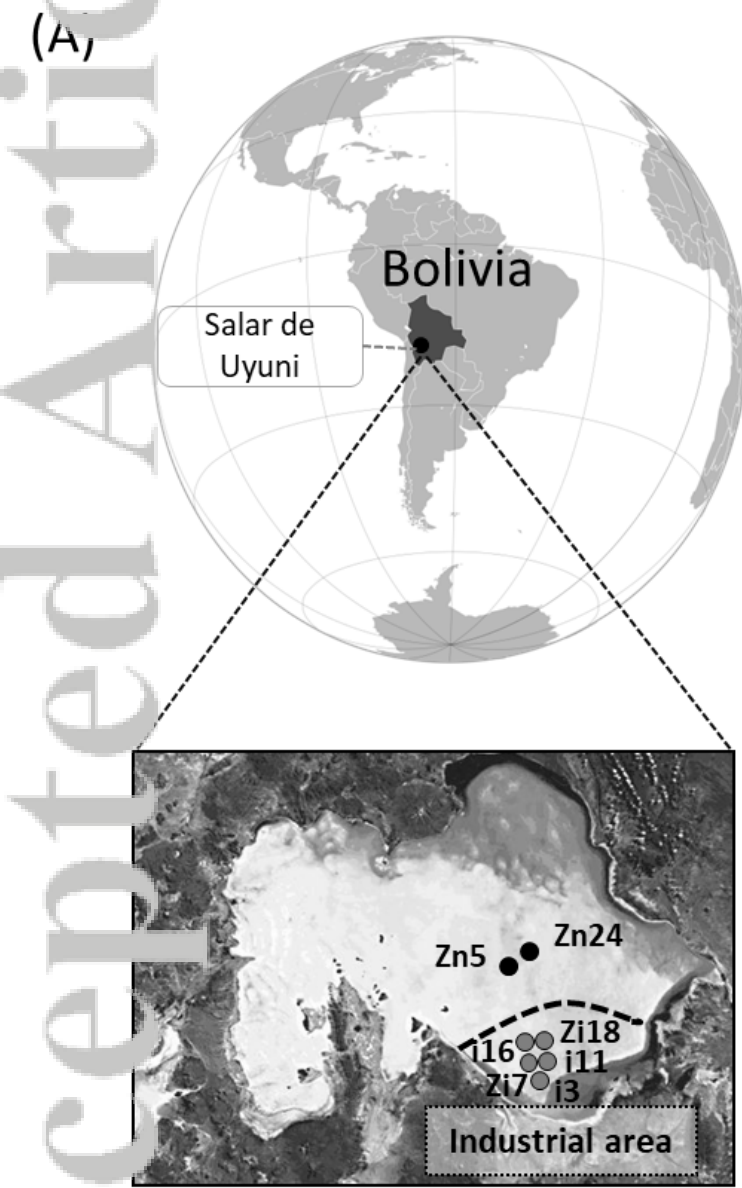

(B)

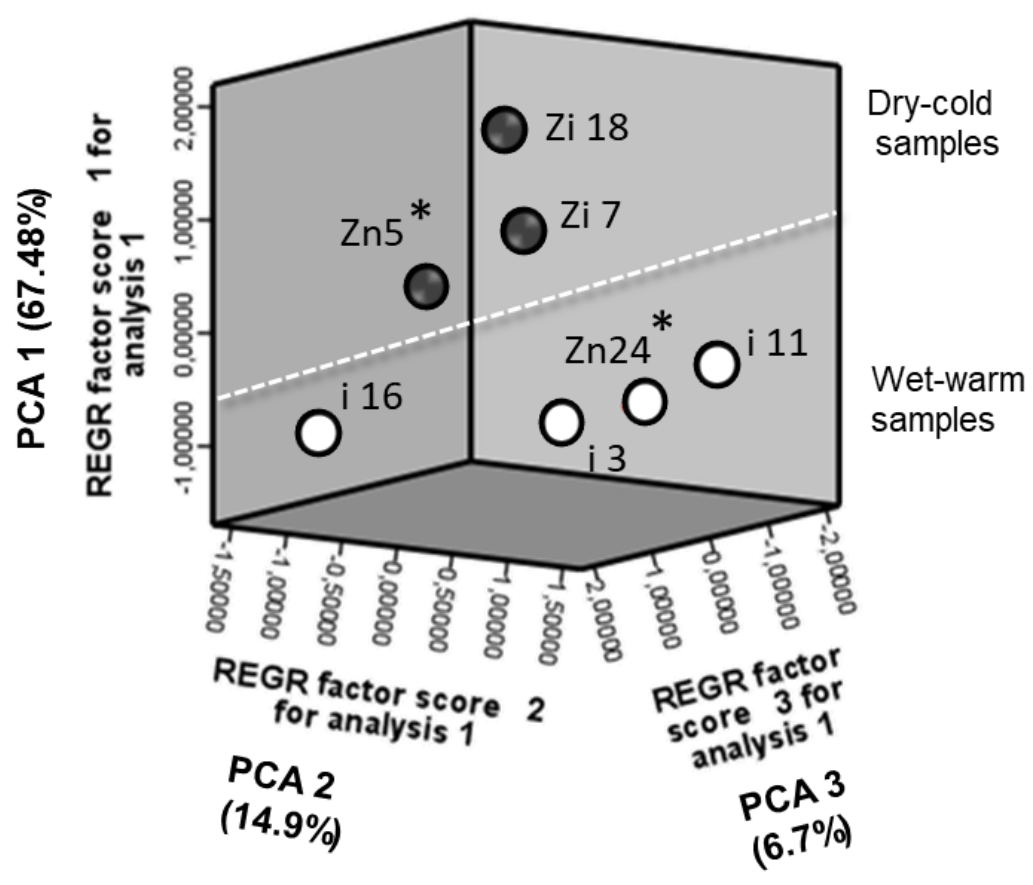


(A)
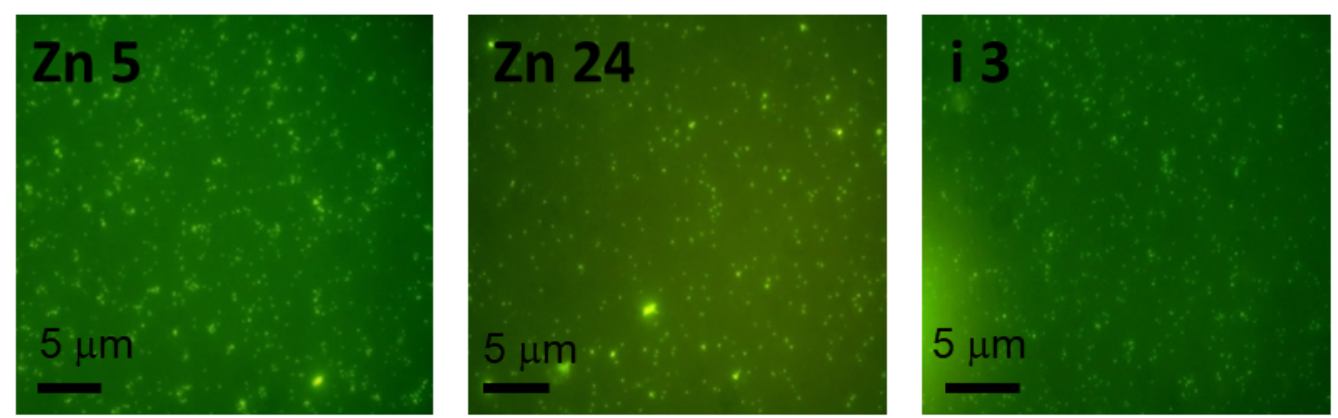

(B)
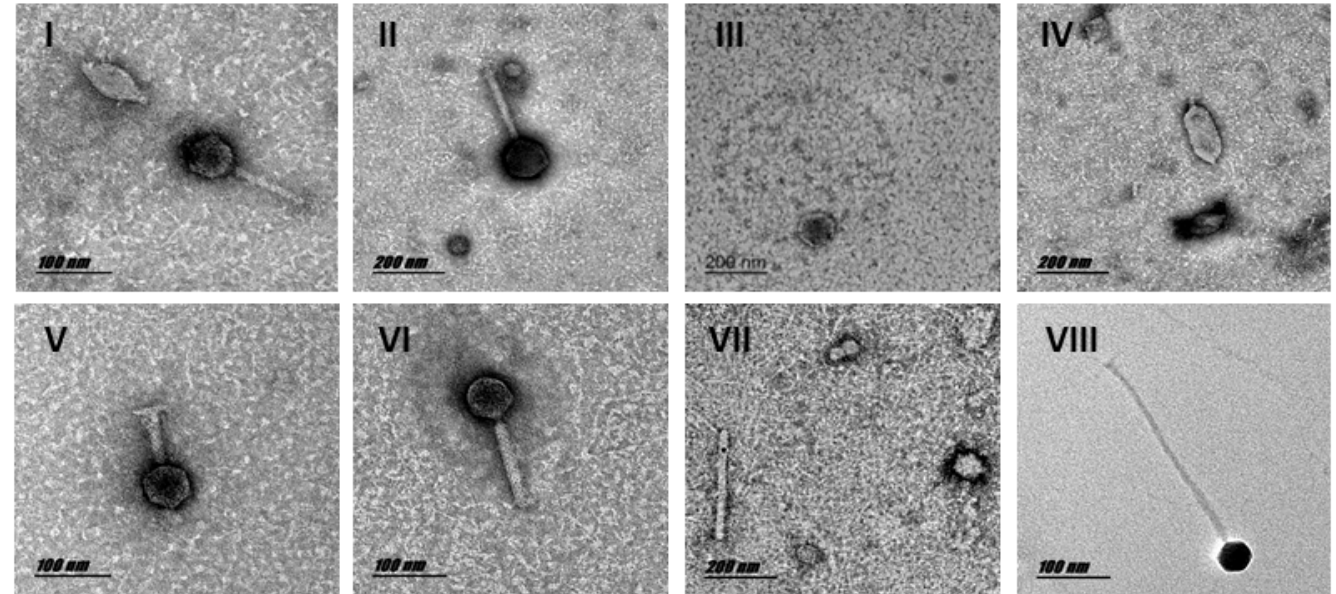

(C)

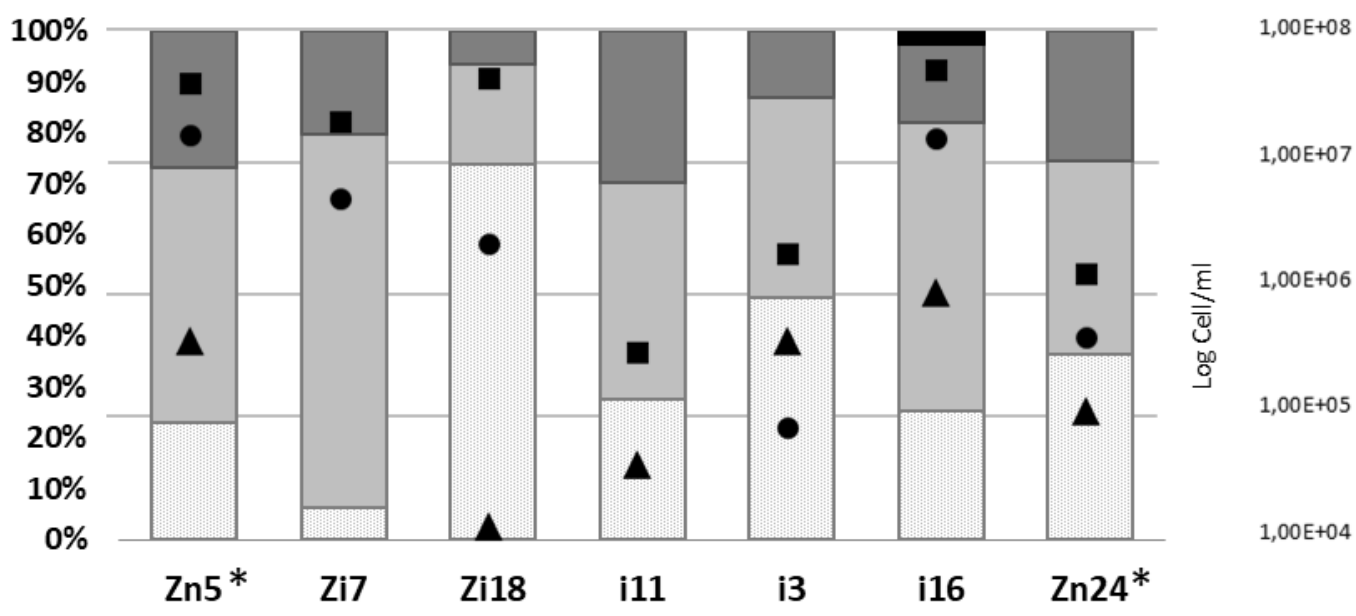

$\square$ Lemon shaped $\square$ Spherical $\square$ Head-tail $\square$ Filament

- DAPI

- Bacteria

A Archaea 


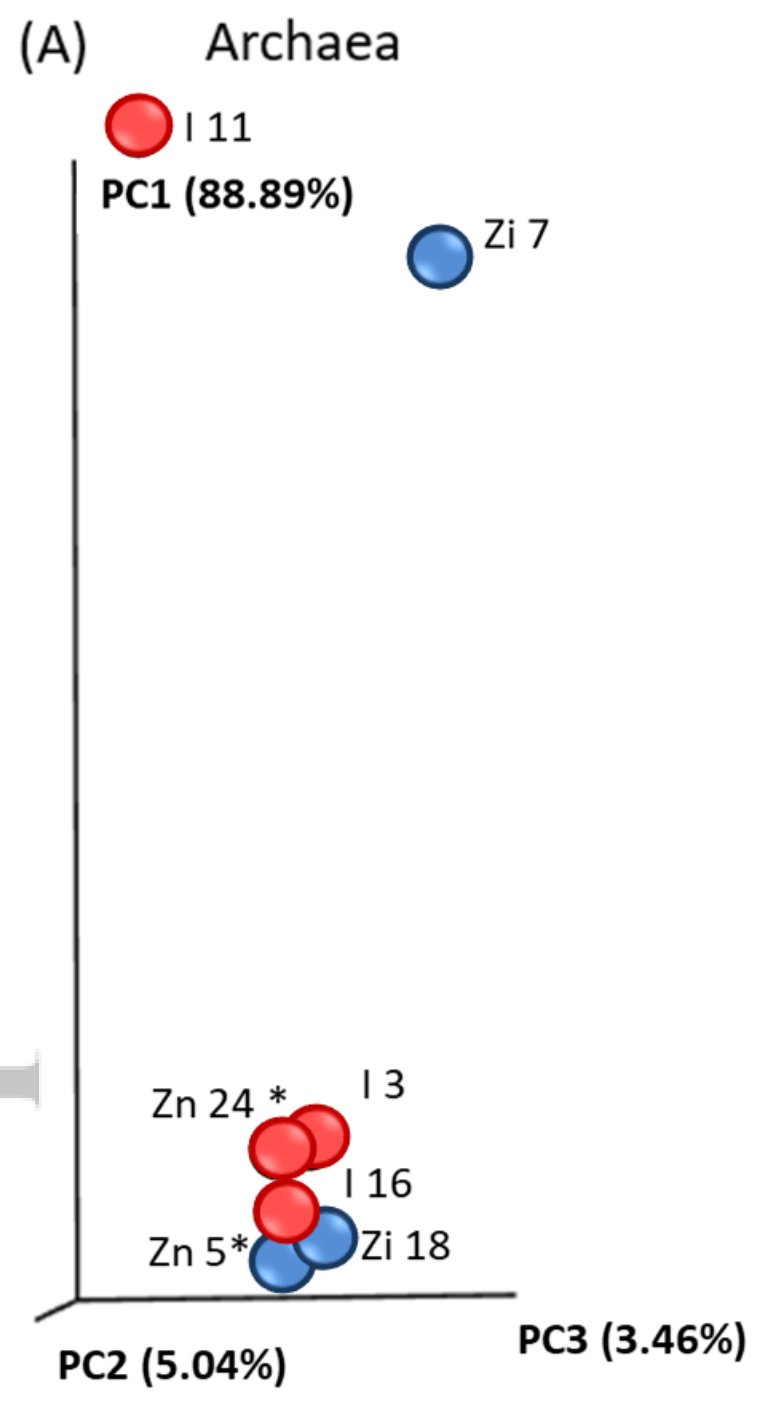

(B) Bacteria

Zi 18

PC1 (69.22\%)

$\bigcirc^{\operatorname{Zn} 24^{*}}$

$1110^{13} \bigcirc^{2 n 5^{*}}$

$0^{116}$

$\mathrm{O}^{\mathrm{Zi} 7}$

PC2 (20.65\%)

PC3 (6\%) 
(A)

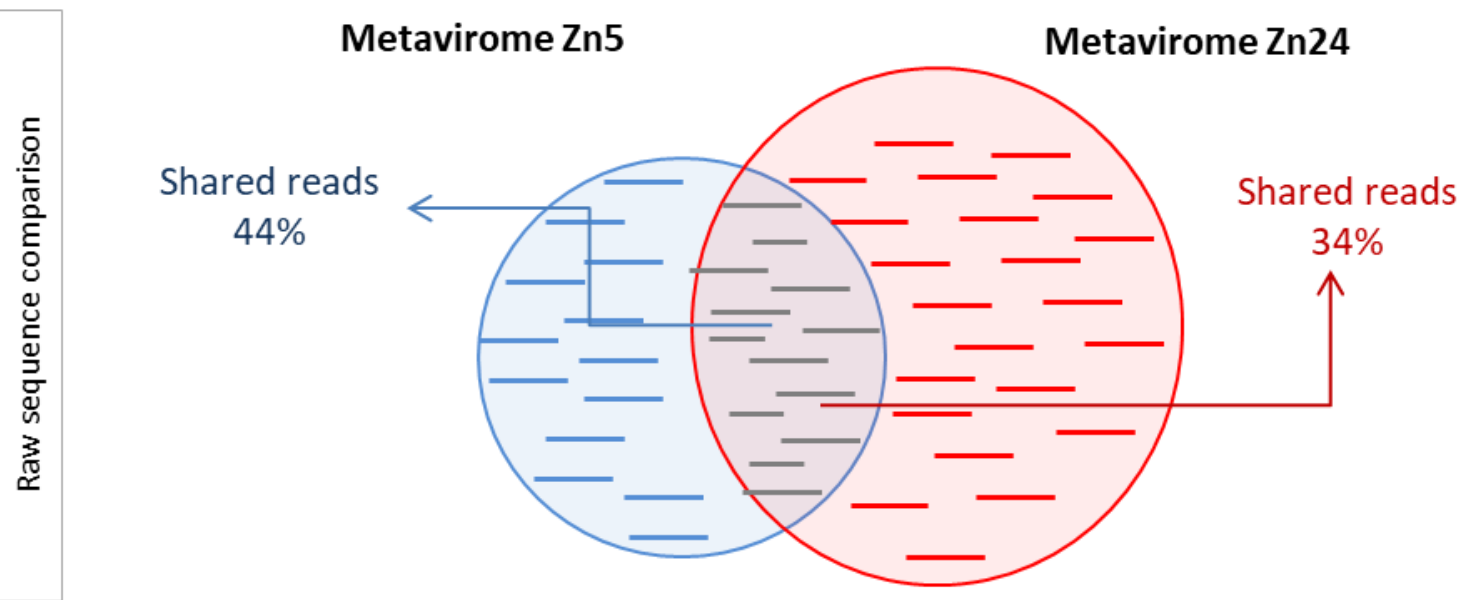

(B)
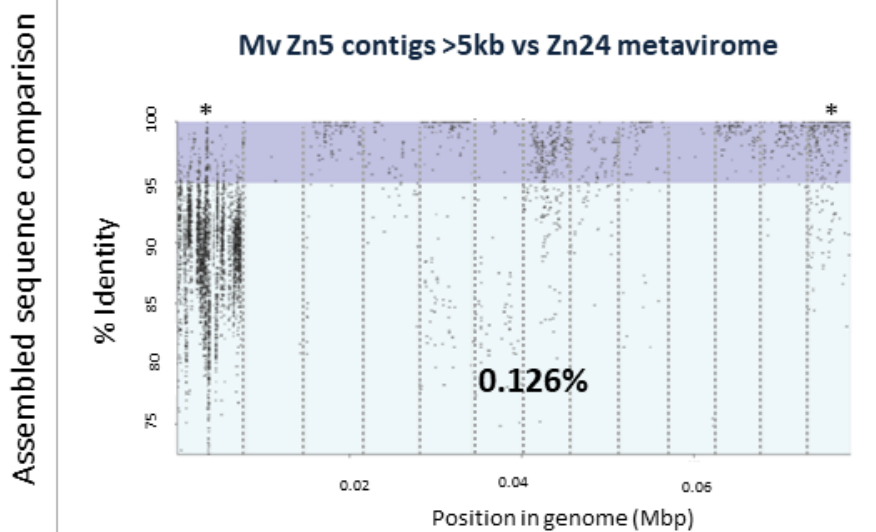

MV Zn24 contigs $>5 \mathrm{~kb}$ vs $\mathrm{Zn} 5$ metavirome

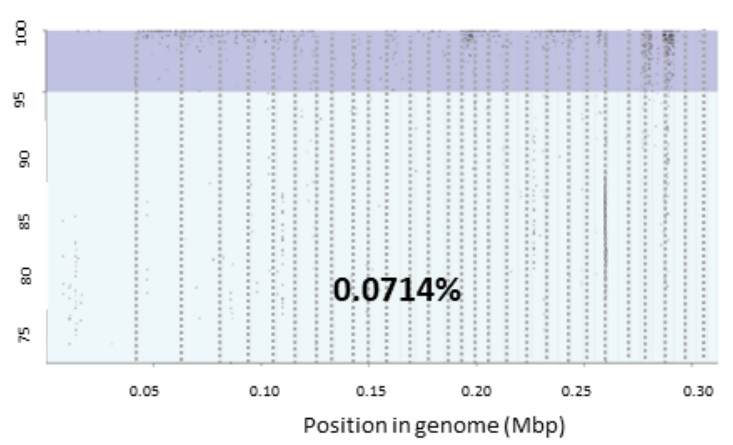

I I

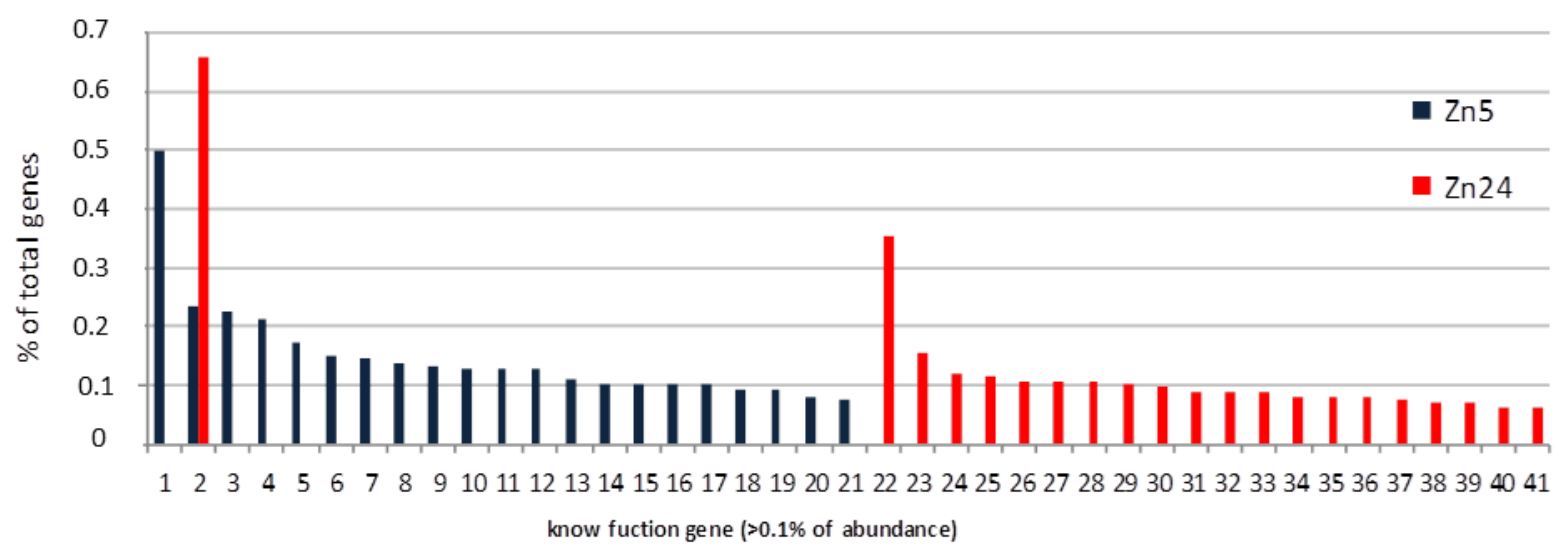


(B)

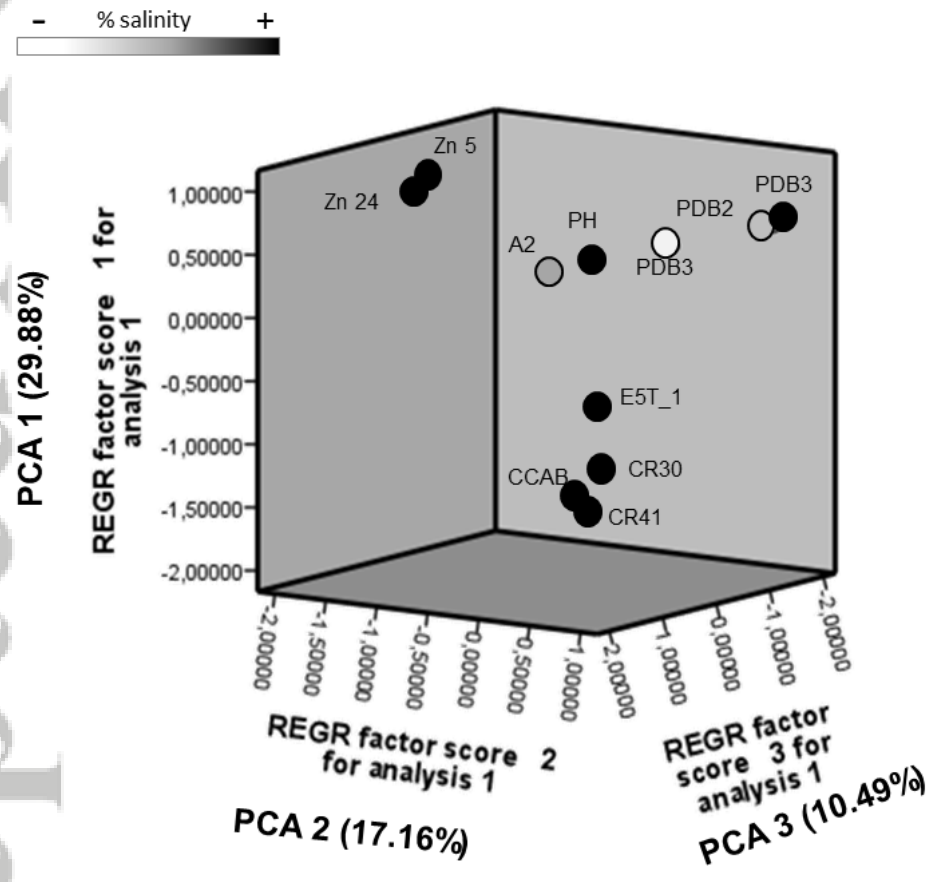

\begin{tabular}{cc}
\hline $\begin{array}{c}\text { Metavirome } \\
\text { ID in plot }\end{array}$ & Metavirome ID \\
\hline Zn 5 & Uyuni metavirome \\
Zn 24 & Uyuni metavirome \\
CR30 & Bras del Port saltern (high salt) $^{3}$ \\
CR41 & Bras del Port saltern (high salt) $^{3}$ \\
CCAB & Bras del Port saltern (high salt) $^{3}$ \\
E5T_1 & Campos saltern (high salt) ${ }^{3}$ \\
A2 & Añana saltern (high salt) ${ }^{3}$ \\
PH & Peña Hueca saltern (high salt) ${ }^{3}$ \\
PDB1 & Hypersaline Saltern high 111605 ${ }^{1}$ \\
PDB2 & Hypersaline-saltern medium 112205 1 \\
PDB3 & Hypersaline Saltern low 112805 ${ }^{1}$ \\
\hline
\end{tabular}

(1) Rodriguez-Brito et al. 2010 (2) Roux et al. 2016

(3) unpublished metaviromes. 